\title{
Vinil ve Çimento Esaslı Cephe Kaplamaların Çevresel Performanslarının İncelenmesi
}

\author{
Neslihan DOĞAN ${ }^{1 *}$ \\ ORCID 1: 0000-0001-5997-3876 \\ ${ }^{1}$ Bursa Uludağ Üniversitesi, Fen Bilimleri Enstitüsü, Mimarlık Ana bilim Dalı, 16120, Bursa, Türkiye. \\ Öz \\ *e-mail: 512012007@ogr.uludag.edu.tr
}

Yaşam döngüsü değerlendirme (YDD), malzemelerin yaşam döngüsü boyunca çevreye verdikleri etkilerin değerlendirilmesi yöntemidir. Bu yöntem bir ürünün hammaddelerinin elde edilmesinden başlanarak, üretim, sevkiyat, tüketici tarafından kullanım ve kullanım sonrası bertaraf aşamalarından oluşan süreci tanımlamaktadır. Bu çalışmada günümüzde geniş bir kullanıma sahip olan cephe kaplama malzemelerinden vinil kaplama ve çimento esaslı cephe kaplama malzemelerinin yaşam döngüsü değerlendirme yöntemi kapsamında BEES (Building for Environmental and Economic Sustainability) yazılımı ile çevresel etkilerine ulaşılmış, elde edilen veriler üzerinden malzemelerin çevreye etkileri karşılaştırmalı incelenmiştir. Bu inceleme ile yapı malzemesinin yapıda kullanım öncesinde çevresel etkilerinin tartışılması ve bu sayede doğaya en az zararlı malzeme seçimlerinin yapılmasına katkı sağlamak hedeflenmiştir. Bu bağlamda çimento esaslı cephe kaplama malzemesinin yaşam döngüsü içerisinde çevresel performans değeri daha yüksek dolayısıyla çevreye daha çok zarar verdiğine ulaşılmıştır.

Anahtar Kelimeler: Yaşam döngüsü değerlendirmesi, vinil cephe kaplaması, çimento esaslı cephe kaplaması

\section{Environmental Performance Investigation of Vinyl and Cement- Based Facade Coatings}

\begin{abstract}
Life cycle assessment (LCD) is a method of evaluating the environmental impact of materials throughout their life cycle. This method defines the process starting from the acquisition of the raw materials of a product, consisting of production, shipment, use by the consumer and disposal after use. In this study, environmental effects of vinyl coating and cement-based facade coating materials, which are widely used today, were reached with BEES (Building for Environmental and Economic Sustainability) software within the scope of the life cycle evaluation method, and the effects of materials on the environment were examined comparatively. With this review, it is aimed to discuss the environmental effects of the building material before its use in the building and thus to contribute to the selection of materials that are least harmful to nature. In this context, it has been reached that the environmental performance value of the cement-based facade cladding material is higher in its life cycle, therefore it causes more damage to the environment.
\end{abstract}

Keywords: Life cycle assessment, vinyl siding, cement based siding

Citation/Atıf: Doğan, N. (2021). Vinil ve çimento esaslı cephe kaplamaların çevresel performanslarının incelenmesi. Journal of Architectural Sciences and Applications, 6 (2), 494-508.

DOI: https://doi.org/10.30785/mbud.889164 


\section{Giriş}

İkinci Dünya Savaşı sonrası kıta Avrupası'nda kent merkezlerinde ve savaşın yaşandığı şehirlerde büyük ölçekte kentsel tahribatlar meydana gelmiştir. Avrupa kıtasının neredeyse tamamında hâkim olan bu tahribatı önlemek için savaş sonrasında kentleşme hızlanmıştır. Kentsel onarımların yanı sıra Ingiltere'den başlayarak ilerleyen sanayileşme çabaları, tüm kıta Avrupa'sına yayılmış ve kentler hızlıca göç almıştır. Çöküntü alanlarını kente katmak ve artan barınma taleplerini karşılamak için bina yapım faaliyetleri hızlanmıştır. Savaş sonrası benimsenen kentsel ve bölgesel kalkınma çabaları birçok ülkeyi gelişmiş ülke yolunda ilerlemesine katkıda bulunsa da insanlık bir dizi sorunlarla baş etmek zorunda kalmışır. Kentlerdeki "hızlı yapılaşma" beraberinde kontrolsüz büyüme önemli ölçüde atık sorunlarını ve çevre sorunlarını beraberinde getirmiştir. Biyosferde artan çevre kirliliğini azaltmak ve önlemek amacıyla yapılan çalışmalar yapılmış ve bu çalışmaların neticesinde sürdürülebilirlik kavramı doğmuştur. Sürdürülebilirlik, bireylerin ihtiyaçlarını gelecek nesillerin ihtiyaçlarından ödün vermeden karşılayabilmesidir. Sürdürülebilirlik, sürdürülebilir kalkınmayı da hedefleyen bir kavram olup birçok sektörde olduğu gibi inşaat sektöründe de geniş yer tutmaktadır. İnşaat sektöründe sürdürülebilirlik kavramı, çevre dostu binalar üretimi faaliyeti olarak değerlendirilmekte ve burada kaynakların kullanım düzeyinin, bu kaynakların kendini yenileme hızını; salınan kirleticilerin oranının, doğal kaynakların bu kirleticileri işleme tabii tutma hızını aşmaması gerekmektedir. Yapı-malzeme sektöründe ise sürdürülebilirlik kapsamında ürünlerin çevresel performanslarının değerlendirme, denetleme ve sertifikalandırma işlemleri yapılmaktadır (California Environmental Protection Agency, 1999; Kaypak, 2011).

Doğal kaynakların bilinçsizce kullanımı bu kaynakların tükenmek noktasına gelebileceği düşüncesi, çevreye olan zararı en aza indirgeyen sürdürülebilir binaların yapılması gerekliliğini göstermektedir. Bu sebeplerden dolayı yapılarda yeşil bina kriterlerinin sağlanabilmesi için bütün dünyada kabul gören çeşitli yönetmelikler ve yeşil bina değerlendirme sistemleri oluşturulmuştur (Özgünler, Acun ve Arpacıoğlu, 2014). Çeşitli ülkeler tarafından kullanılan ve kabul gören sertifika sistemleri BREEAM (Building Research Establishment Environmental Assessment Method), LEED (Leadership in Energy and Environmental Design), DGNB (Deutshe Gesellschaft für Nachhaltiges Bauen e.V.), IISBE (International Initiative for Sustainable Built Environment), Greenstar (Enviromental Raiting System for Buildings), Casbee (Comprehensive Assessment System for Built Environment Efficiency) olarak sıralanabilir. Sertifika sistemleri; arazi seçiminden başlayarak, bina formunun belirlenmesi, enerji verimliliğinin sağlanması, yenilenebilir enerji kullanımı, enerji etkin aydınlatma, su yönetimi, çevreye duyarlı sürdürülebilir malzeme seçimi, iç hava kalitesinin sağlanması ve binanın tüm yaşam döngüsünde çevresel çıkarları ön planda tutan yaklaşım benimser.

Yeşil bina sertifikasyon sistemlerinin yanı sıra yapı malzemelerinin yaşam döngüsü değerlendirmesinin ölçüldüğü çeşitli yazılımlar geliştirilmiştir. BEES (Building for Environmental and Economic Sustainability) yazııımı, yaşam döngüsü olarak bilinen çok disiplinli yaklaşım kullanılarak seçilen ürünlerin çevresel ve ekonomik performansı ölçülmektedir. Sistemde kayıtlı malzemeler yaşam döngüsü değerlendirme olarak adlandırılan çevresel faktörleri değerlendirmek için "beşikten mezara" yaklaşımı kullanılmaktadır. BEES, Uluslararası Standartlar Organizasyonu (ISO) tarafından standartlaştırılmış performansı içermektedir. Bu bağlamda çalışmada, malzemelerin yaşam döngüsü değerlendirme sisteminin önemini belirtmek, tasarımcıların- mimarların yapı malzemesi seçimlerinde çevresel gösterge olan yaşam döngüsü değerlendirme yöntemi ile çevresel tahribatı en az olan yapı malzemelerinin seçimine dikkat çekmek hedeflenmiştir.

Çalışma, 230 dan fazla yapı ürünü için çevresel ve ekonomik performans verilerini içeren BEES Online veri tabanından seçilen vinil ve çimento esaslı dış cephe kaplama malzemelerinin BEES simülasyon yöntemi ile çevresel etkilerinin değerlendirilmesini kapsamaktadır. Çalışmada öncelikle yaşam döngüsü değerlendirme ve BEES simülasyon yöntemi ve veri tabanı tanıtılmış, sonrasında seçilen malzemelerin BEES veri tabanı ile yaşam döngülerinin değerlendirilmesi yapıımıştır. Yapılan analizler ile yapı ve malzeme sektöründe hizmet veren mimarlar, mühendisler ve inşaat firmaları için yapım öncesi seçilen malzemelerin yaşam döngüleri içerisinde çevresel etkilerinin izlenmesi, malzeme seçimlerinin bu 
parametreler göz önüne alınarak yapılması ve yapım sürecinin içerisinde yer alan kişilerin bu süreçle birlikte çevre bilincini artırmaları hedeflenmiştir.

Yapı malzemelerinin yaşam döngüsü değerlendirme çalışmalarında malzeme çeşitliliğinin çok olması ve malzeme üretim aşamalarının çok fazla girdili süreçler ile takip edilmesi nedeniyle malzemeler hakkındaki verilerin toplanması için belirli bir zaman gerekmektedir. Değerlendirilmelerin, kontrol ve iyileştirilmelerin yapılabilmesi için zengin bir veri tabanı gereklidir. Yaşam döngüsü değerlendirme hakkında ülkemizde geliştirilen bir veri tabanı olmamakla birlikte, uluslararası veri tabanlarının modellerinden faydalanılarak ulusal bir yaşam döngüsü değerlendirme veri tabanı oluşturulabilir (Öztaş ve Tanaçan, 2017). Oluşturulan veri tabanında yer alan veriler ise çeşitli kamu kurum ve kuruluşlarının temsilcileri tarafından denetlenerek bilgilerin kontrolü yapılmalıdır. Bu kapsamda Türkiye'de yapı sektöründe yer alan aktörlerin görev tanımlarının belirlenmesi ve uygulama pratiği kazanarak bu sürecin içerisinde yer almaları beklenmektedir (Çelebi ve Gültekin, 2016). Oluşturulan veri tabanı mimarlara ve tasarımcılara estetik, ekonomi, uygulama kolaylığı ve malzemelerin çevresel etkileri hakkında bilinçli bir seçim yapmalarına olanak sağlayacaktır. Bu nedenle Türkiye için sürdürülebilir bir materyal kütüphanesi geliştirilmeli ve aynı zamanda birçok bilgi de paylaşılmalıdır. Malzeme üreticileri ise bu yolla ürünlerin çevre üzerindeki yükünü azaltmanın yollarını tartışma ve geliştirme süreçlerinde aktif rol oynayacaktır. Ulusal bir yaşam döngüsü değerlendirme veri tabanı ile sürdürülebilir bir gelecek için araştırma-geliştirme birimleriyle daha sürdürülebilir ürünler elde edebilmek ve ürünlerin çevreye verdikleri zararları en aza indirmek mümkün olacaktır.

\subsection{Yaşam Döngüsü Değerlendirme}

Yaşam döngüsü değerlendirme, Eylül 1995'de yayınlanan Türk Standartlarına göre malzemelerin yaşam döngüsü boyunca çevreye verdikleri etkilerin değerlendirilmesi yöntemidir. Çevre bilincinin artmasıyla birlikte yaşam döngüsü değerlendirme; (TS EN ISO 14040,2006; Finnveden, Hauschild, Ekvall, Guinee, Heijungs, Hellweg ve diğerleri, 2009; Yılmaz ve Arslan, 2018).

Ürünlerin hayat boyu değerlendirme süreçleri planlama, ürün tasarımı ya da yeniden tasarım amacıyla sanayi tesislerinde, kamu kurum ve kuruluşlarında, pazarlamada (çevre etiketi uygulaması, çevresel bir beyanın hazırlanması veya çevresel ürün açıklaması geliştirilmesinde) yardımcı olabilir. Bu yöntem bir ürünün hammaddelerinin elde edilmesinden başlanarak, üretim, sevkiyat, tüketici tarafından kullanım ve kullanım sonrası bertaraf aşamalarından oluşan süreci tanımlamaktadır (TS EN ISO 14040,2006; Finnveden ve diğerleri, 2009; Yılmaz ve Arslan, 2018).

Yaşam döngüsü değerlendirilmesi tanımı, malzeme ve enerji kaynaklarına duyulan artış nedeniyle 1960'larda ortaya çıkmıştır.1980'lerde Bekker'in “Paslanmaz Çelikte Yeşil Kum Döküm ve CNC Frezelemeye Kıyasla Tel + Ark Katmanlı İmalatın Yaşam Döngüsü Değerlendirmesi" çalışması inşaat sektöründe ilgi çekmiştir (Bekker ve Verlinden, 2018). 1990'larda ise yaşam döngüsü değerlendirmesi hakkında çeşitli seminerler düzenlenmiş ve yazılı kaynaklar basılmıştır. 1994 yılından sonra International Organization for Standardization (ISO) konuya dâhil olarak 1997 yılında ilk defa basılan 14040 standart serisini oluşturmuştur (TS EN ISO 14040,2006; Finnveden ve diğerleri, 2009; Klöpffer, 1997). Bu standart serisi, yöntem açısından bir çerçeve oluşturmuş ve farklı YDD çalışmalarının karşılaştırılabilmesi açısından kolaylık sağlamıştır (Yıldız, 2017). 2000 yılından sonra Çevresel Toksikoloji ve Kimya Topluluğu (Society of Environmental Toxicology and Chemistry, SETAC) Yaşam Döngü Değerlendirmesi konusunda uzmanları bir araya getirerek, terminoloji ve metodolojiyi "Code of Practice" (Uygulama Kuralları) adı altında yayınlamıştır (Buyle, Breat ve Audenaret,2013). SETAC tarafından yaşam döngüsü değerlendirme hakkında birçok yayın olmakla birlikte, "Environmental Life Cycle Costing" isimli yayın, yaşam döngüsü maliyetlendirmesi ve yaşam döngüsü değerlendirmesi arasındaki bağlantıyı sunulmakta ve ardından kamu, özel ve toplumsal işbirliğine vurgu yapması açısından önemlidir (Hunkeler, Lichtenvort ve Rebitzer,2008).

Yaşam döngüsü değerlendirme uygulaması, süreç içerisinde çevresel zararları önlemeyi ve gereksiz harcamaların önüne geçmeyi hedefler. Yaşam döngüsü düşüncesi kavramına dayanan yaşam döngüsü değerlendirmesi (YDD), ürünlerin, hizmetlerin ve süreçlerin tüm yaşam döngüleri boyunca olası 
çevresel etkilerini değerlendirmek için sistematik bir yöntemdir. YDD yöntemi 4 adımda değerlendirilmektedir. Bu adımlar;

- Amaç ve kapsam tanımı

- Yaşam döngüsü veri analizi

- Yaşam döngüsü etki değerlendirmesi

- Yaşam döngüsü yorumu olarak tanımlanmaktadır.

1. Amaç ve Kapsam Tanımı: Bu bölümde çalışmanın amacı, kapsamı, sistem sınırları belirlenmiştir.

2. Yaşam Döngüsü Veri Analizi: Bu evrede sistemin sınırları kapsamında oluşan enerji, su, ham madde kullanımı ve bunlara bağı ı̧evresel salınımlar belirlenir.

3. Yaşam Döngüsü Etki Değerlendirmesi: Belirlenen çevresel salınımların insan sağlığı kriterleri ve çevreye etkileri değerlendirilir.

4. Yaşam Döngüsü Yorumu: Bu aşamada envanter ve etki analizi aşamalarının sonuçları değerlendirilerek karşılaştırılanlar arasından tercih edilecek ürün, süreç ya da hizmet seçilir. Bu seçim esnasında yapılan tahminler ve var olan belirsizlikler YDA kapsamında açık bir şekilde belirtilir (Yılmaz ve Arslan, 2018).

\subsection{BEES Yazılımı}

BEES (Building for Environmental and Economic Sustainability), NIST (Ulusal Standartlar Teknoloji Enstitüsü) Mühendislik Laboratuvarı tarafından geliştirilen, fikir birliği standartlarına dayalı, pratik, esnek ve şeffaf olacak şekilde tasarlanan bir yazılımdır. Mimarları, tasarımcıları, inşaat mühendislerini ve ürün üreticilerini hedef kitlesi olarak gören BEES Online, 230 dan fazla yapı ürünü için çevresel ve ekonomik performans verilerini içermektedir. BEES, ISO 14040 serisi standartlarda belirtilen yaşam döngüsü değerlendirme yaklaşımını kullanarak yapı ürünlerinin çevresel performansını ölçer. Bir ürünün ömrünün tüm aşamaları -hammadde edinimi, üretimi, nakliyesi, kurulumu, kullanımı ve geri dönüşümü ve atık yönetimi- analiz edilir. BEES yazılımında, ekonomik performans değeri ilk yatırım, değiştirme, işletme, bakım ve onarım ve bertaraf maliyetlerini kapsayan ASTM (American Society for Testing and Materials) standart yaşam döngüsü maliyet yöntemi kullanılarak ölçülür. Çevresel ve ekonomik performansı sağlamak ve çok nitelikli karar analizi için ASTM standardı kullanılarak genel bir performans ölçüsünde birleştirilir. Tüm BEES analizleri için, yapı ürünleri UNIFORMAT II olarak bilinen yapı elemanları için ASTM standart sınıflandırmasına göre tanımlanır ve sınıflandırılır. BEES için hedef iki yönlüdür: (Greig ve Kneifel, 2021; Kneifel ve Layappa, 2021; Lippiatt, 2002).

Üreticilerin uygun maliyetli sürdürülebilir bina ürünleri geliştirmelerine ve kullanımına katkıda bulunmak,

Mimarlar, tasarımcılar, devlet kurumları gibi geniş bir paydaş yelpazesine sahip olup, kullanıcıları bilgilendirmektir.

BEES, Yaşam Döngüsü olarak bilinen çok disiplinli yaklaşımı kullanarak çevresel performansı ölçmektedir. Sistemde kayıtlı malzemeler yaşam döngüsü değerlendirme olarak adlandırılan çevresel ölçümleri ölçmek için "beşikten mezara" yaklaşımı ile değerlendirilmektedir. BEES, Uluslararası Standartlar Organizasyonu (ISO) tarafından standartlaştırılmış performansı içermektedir. Bir ürünün yaşamındaki tüm aşamaların çevresel etkiler oluşturduğundan dolayı hammadde edinimi, ürün imalatı, nakliye, kurulum, operasyon, bakım, geri dönüşüm ve atık yönetimi aşamalarını kapsamaktadır (NIST,2021). Yaşam döngüsü değerlendirmesi gücü kapsamlı, çok boyutlu kapsamıdır. BEES, kapsamında ilerleyen yaşam döngüsü değerlendirme dört adımdan oluşur. (Greig ve Kneifel, 2021; Kneifel ve Layappa, 2021; Lippiatt, 2002).

Amaç ve kapsam tanımlama aşamasında, çalışmanın amacı, genişliğini ve derinliğini açıklanır. 
Envanter analizi aşamasında, tüm yaşam döngüsü boyunca bir ürünle ilgili çevresel girdileri, çıktıları tanımlar ve nitelendirilir. Çevresel girdiler arasında su, enerji ve diğer kaynaklar; çıktılar havaya, karaya ve suya salınımları içermektedir.

Etki değerlendirmesi aşamasında, çevresel etkiler değerlendirilir.

Yorumlama adımında, malzemelerin çevresel etkileri projenin hedefleri doğrultusunda birleştirilir. Ürünlerin seçimleri yapıldıktan sonra BEES tarafından yaşam döngüsü analizi yapılmaktadır (Scheuer \& Keoleian 2002).

\section{Materyal ve Yöntem}

Çimento esaslı dış cephe kaplama malzemesi boyanabilir ve boya tutuculuğu yüksek sürdürülebilir bir malzeme çeşididir. Neme ve biyolojik atıklara karşı dayanımı yüksektir. Yüzeye dik eğilme dayanımı $9 \mathrm{~N} / \mathrm{mm}^{2}$ dir. Depreme karşı dayanıklı geri dönüşümlü bir malzemedir. Vinil dış cephe kaplaması plastik esaslı yangına karşı yüksek dayanım gösteren bir malzemedir. Gözenekli yapısı ile yapıya nefes aldırmaktadır. Kolayca şekil alabilme özelliği ile üretim maliyeti düşüktür. Geri dönüşümlü bir malzeme olup solvent içermez (Certain Teed Corporation,2021).

Vinil ve çimento esaslı dış cephe kaplama malzemelerinin çevresel etkileri kapsamında hazırlanan bu çalışma, literatür taraması, uygulama ve öznel değerlendirme çalışması sonucunda gerçekleştirilmiştir. Çalışmanın literatür taraması bölümünde yaşam döngüsü değerlendirmesinin tanımı, yaşam döngüsü kavramının tarihsel gelişim, tanımın inşaat sektörüne katkıları ve ulusal-uluslararası örnek çalışmalardan bahsedilerek konu hakkında bilgi birikimi oluşturmak hedeflenmiştir. Araştırma olgu ve olayları nesnelleştirerek gözlemlenebilir, ölçülebilir ve sayısal olarak ifade edilebilir bir şekilde ortaya koyması sebebiyle nicel bir araştırmadır.

Çalışmanın uygulama bölümünde, BEES simülasyon programı ve veri tabanı yardımıyla seçilen malzemelerin çevresel ve ekonomik performansları incelenmiştir. İnceleme yapılan çevresel kriterler hakkında detaylı bilgiler verilmiştir.

Çalışmanın sonucunda, vinil ve çimento esaslı cephe kaplamalarını farklı kategorilerde çevresel etki değerleri belirtilmiştir. Yapılan analiz ile birlikte malzeme seçimlerinde çevresel etki sınıflarının önemi vurgulanmak istenmiştir.

\section{Araştırma Bulguları}

Bu bölümde BEES simülasyon yöntemi kullanılarak, vinil ve çimento esaslı dış cephe kaplama malzemelerinin hayat boyu değerlendirme yöntemi kapsamında, çevresel etkileri değerlendirilmiştir. Bu çalışma BEES yazııımından elde edilen bilgiler doğrultusunda yapıımıştır.

Vinil dış cephe kaplaması, 1960'lardan beri Türkiye'de yaygın olarak kullanılmaktadır. Polivinil Klorür esaslı malzeme binalarda yalıtım sağlamak ve estetik bir görünüm elde etmek için kullanılmaktadır. Masif görünümlü, yangına karşı yüksek dayanımlı, hafif ve yapıyı nefes aldıran bir yapıya sahiptir (Şekil 1). Çimento esaslı dış cephe kaplaması, yüksek su buharı geçirgenliği sayesinde yüzeylerin nefes almasına olanak tanır (Şekil 2).

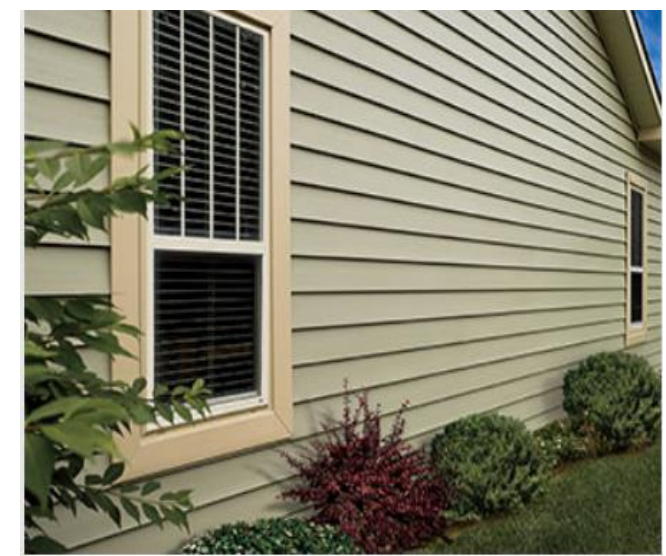

Şekil 1. Vinil dış cephe kaplaması (Certain Teed Corporation, 2021) 


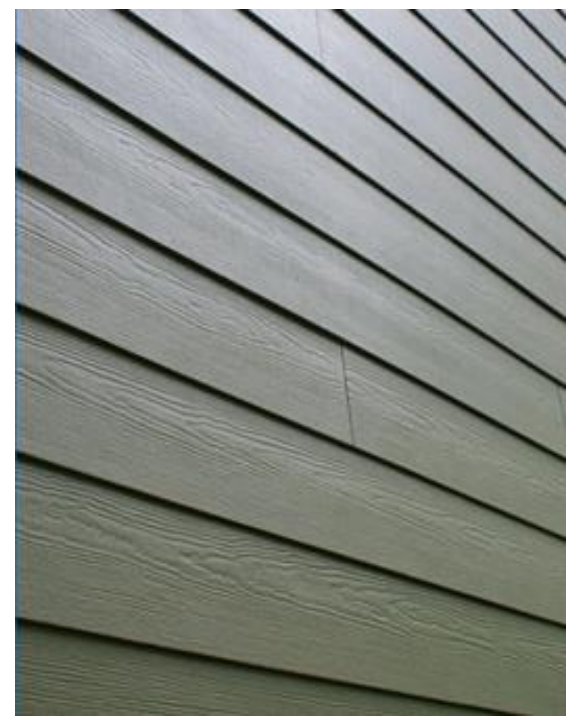

Şekil 2. Çimento esaslı cephe kaplaması (Certain Teed Corporation, 2021).

\subsection{Vinil Dış Cephe Kaplamasının Yaşam Döngüsü Kapsamı ve Veri Analizi}

Bu bölümde vinil dış cephe kaplama malzemesi hayat boyu değerlendirme yöntemi kapsamında değerlendirilmiştir. Bu kapsamda malzemenin amaç, kapsam tanımı ve yaşam döngüsü veri analizine yer verilmiştir.

\subsubsection{Amaç ve kapsam tanımı}

Bu bölümde cephe kaplama malzemesi olarak vinil dış cephe kaplama malzemesi incelenmiş, malzemenin üretim evresinden geri dönüşüm evresine kadar olan süreci ele alınmıştır. CertainTeed'in BEES'teki vinil kaplama ürünü ortalama olarak modellenmiştir (Şekil 3). Fabrikalarda üretilen vinil kaplama ürün serilerinin malzeme listeleri, üretim verileri toplanmış ve ortalaması alınmıştır. Bu vinil kaplama, nominal kalınlığa sahiptir. Çalışmada cephe kaplama malzemelerinin karşılaştırılması için işlevsel birim "100 ft" olarak tanımlanmaktadır (Scheuer ve Keoleian 2002).

- Çalışmanın kapsamı: Vinil kaplamanın yaşam döngüsündeki hammadde çıkarımı, üretim, taşıma evreleridir.

- Çalışmanın birim işlemleri: üretim aşamasında ihtiyaç duyulan enerji miktarı, dış ortama aktarılan madde salımı, kullanılan katı atıklar ve taşıma maliyetidir.

- Çalışmanın sınırları: Hammadde taşınmasında kullanılan teknikler ve her bir teknikteki malzeme, enerji, su gibi girdi akışları ile hava/su/toprağa salımlar, su esaslı atıklar, katı atıklar, yan ürünler gibi çıktı akışlarıdır.

- Çalışmanın veri kalite gerekleri: Vinil dış cephe kaplama malzemesi için zaman, mekân ve teknoloji ile ilgili verileri içermektedir. 


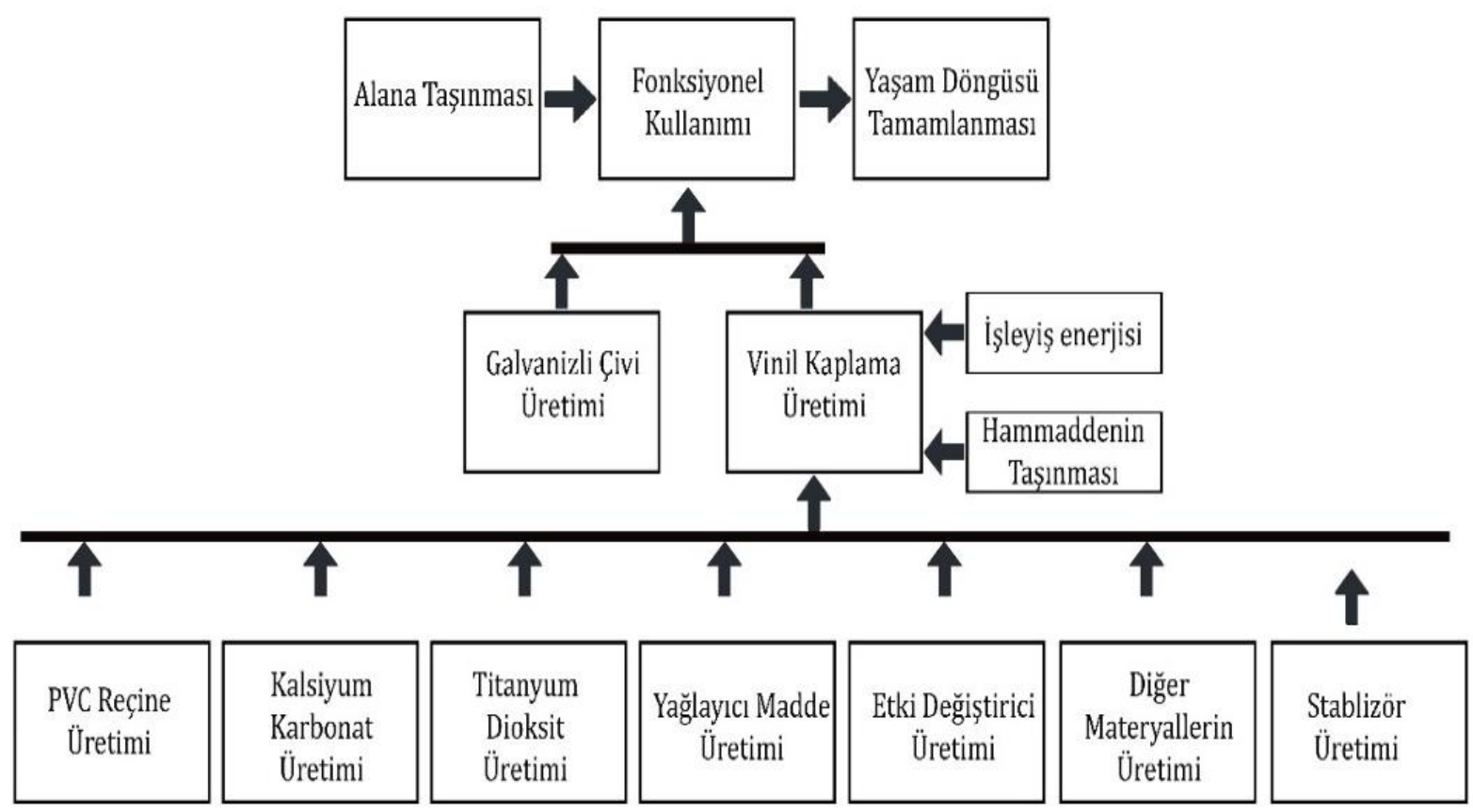

Şekil 3. Vinil dış cephe kaplaması sistem sınırları (Scheuer ve Keoleian, 2002; Kneifel ve Layappa, 2002)

\subsubsection{Vinil dış cephe kaplamasının yaşam döngüsü veri analizi}

Bu aşamada vinil dış cephe kaplama malzemesinin birleşenleri ve sistem sınırlarının kesinleştirilmesi yer almaktadır. Yapı ürününün hammaddesinin elde edilme aşamasındaki çevresel etkilerinin değerlendirilmesinde malzemeye özgü veriler BEES veri tabanından alınmıştır (Çizelge 1). Malzemenin üretimi sırasında tüketilen enerji miktarları Çizelge 2 de gösterilmiştir.

Çizelge 1. Vinil esaslı dış cephe kaplamasının bileşen yüzdeleri (Scheuer ve Keoleian, 2002; Kneifel ve Layappa, 2002)

\begin{tabular}{l|c}
\hline \multicolumn{1}{c}{ Bileşen } & Kütle Miktarı \% \\
\hline PVC Reçine & $8.6-\%$-\% 10.5 \\
\hline Kalsiyum Karbonat & $\% 2.8-\% 3.4$ \\
\hline Akrilik Bazlı Katkılar & $1,5-\% 1,9$ \\
\hline Titanyum Dioksit & $1,4-\% 1,7$ \\
\hline Yağlayıcı Madde & $1,8-\% 2,2$ \\
\hline Diğer Katkılar & \\
\hline
\end{tabular}

Çizelge 2.Vinil esaslı dış cephe kaplaması üretimi için gerekli enerji miktarları (Scheuer ve Keoleian, 2002; Kneifel ve Layappa, 2002)

\begin{tabular}{c|c}
\hline Enerji Türü & Değer(MJ) \\
\hline Elektrik (MJ) & $0.282-0.344$ \\
\hline Doğalgaz (MJ) & $0.028-0.034$ \\
\hline Propan (MJ) & $0.009-0.011$ \\
\hline
\end{tabular}

$100 \mathrm{ft}^{2}$ cephe kaplama malzemesi için ortalama \%5'lik kurulum atığı olduğu ve atıkların bir depolama sahasına gireceği varsayılmaktadır. PVC reçine demiryolu ile ortalama 2500 km (1533 mil) taşındığı, diğer malzemeler ise 500 km uzaklıktan dizel kamyonla taşınmıştır. Üretimi tamamlanmış malzemenin, üretim mekânından ayrılmasından şantiyeye ulaşmasındaki taşıma mesafesi yazılımda kullanıcının seçimine bırakılmıştır. Bu kapsamda üretim mekânı ve şantiye arasındaki mesafe 200 km olarak belirlenmiştir. Malzemelerin üretim öncesinde ve sonrasında taşıma mesafesi ekonomik ve çevresel 
etki yönünden analiz sonuçlarını harcanan yakıt ve bu yakıtın çevreye verdiği zarar bağlamında etkilemiştir. Ürünlerin taşınma esnasında oluşturduğu çevre problemleri ve girdileri de açıklanmıştır.

\section{2. Çimento Esaslı Dış Cephe Kaplamasının Yaşam Döngüsü Kapsamı ve Veri Analizi}

Bu bölümde çimento esaslı dış cephe kaplama malzemesi hayat boyu değerlendirme yöntemi kapsamında değerlendirilmiştir. Bu kapsamda malzemenin amaç, kapsam tanımı ve yaşam döngüsü veri analizine yer verilmiştir.

\subsubsection{Amaç ve kapsam tanımı}

Bu bölümde cephe kaplama malzemesi olarak çimento esaslı dış cephe kaplama malzemesi incelenmiş, malzemenin üretim evresinden geri dönüşüm evresine kadar olan süreci ele alınmıştır (Şekil 4). Çalışmada cephe kaplama malzemelerinin karşılaştırılması için işlevsel birim "100 ft" olarak tanımlanmaktadır (Scheuer ve Keoleian, 2002; Kneifel ve Layappa,2002).

Çalışmanın kapsamı: çimento esaslı dış cephe kaplama malzemesinin yaşam döngüsündeki hammadde çıkarımı, üretim, taşıma evreleridir.

Çalışmanın birim işlemleri: çimento esaslı dış cephe kaplama malzemesinin üretim aşamasında ihtiyaç duyulan enerji miktarı, dış ortama madde salımı, kullanılan katı atıklar ve taşımadır.

Çalışmanın sınırları: Hammadde taşınmasında kullanılan teknikler ve her bir teknikteki malzeme, enerji, su gibi girdi akışları ile hava/su/toprağa salımlar, su esaslı atıklar, katı atıklar, yan ürünler gibi çıktı akışlarıdır.

Çalışmanın veri kalite gerekleri: çimento esaslı dış cephe kaplama malzemesi için zaman, mekân ve teknoloji ile ilgili verileri içermektedir.

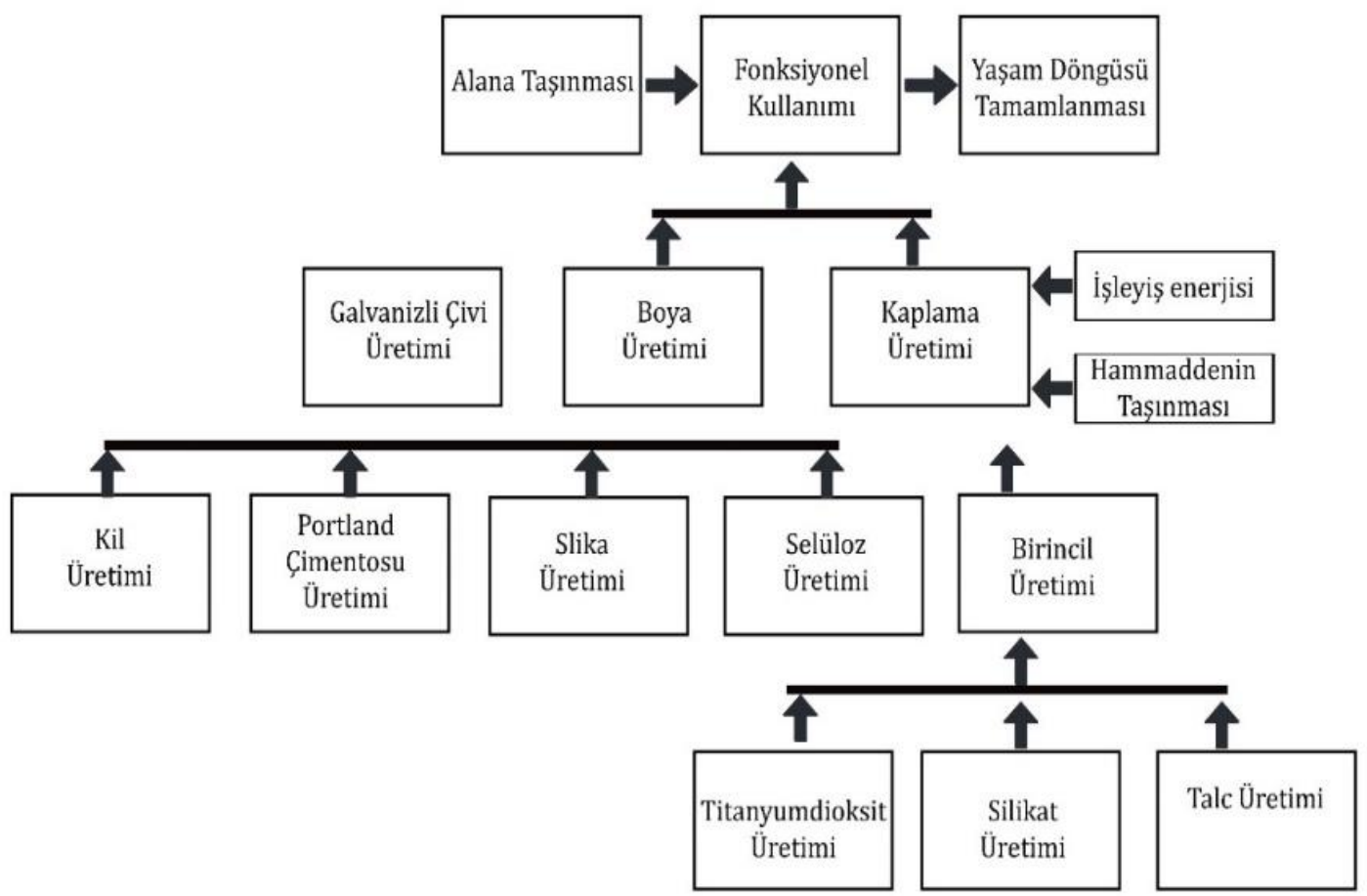

Şekil 4. Çimento esaslı dış cephe kaplaması sistem sınırları (Scheuer ve Keoleian, 2002; Kneifel ve Layappa, 2002)

\subsection{2. Çimento esaslı dış cephe kaplamasının yaşam döngüsü veri analizi}

Bu aşamada yapı ürününün sistemdeki malzeme birleşenleri ve sistem sınırlarının kesinleştirilmesi yer almaktadır. Yapı ürününün hammadde elde edilme aşamasındaki çevreye etkisinin analizinde malzemeye ve hammadde akışlarına özgü veriler BEES veri tabanından alınmıştır (Çizelge 3). Malzemenin üretimi sırasında tüketilen enerji miktarları Çizelge 4 de gösterilmiştir. 
Çizelge 3. Çimento esaslı dış cephe kaplamasının bileşen yüzdeleri (Scheuer ve Keoleian, 2002; Kneifel ve Layappa, 2002)

\begin{tabular}{c|c}
\hline Birleşen & Kütle Miktarı (\%) \\
\hline Portland Çimento & \% 34 ila\% 39 \\
\hline Kaolin kili & \% 2 ila\% 7 \\
\hline Silis & $\% 48$ ila \% 53 \\
\hline Selüloz & $\%$ ila\% 10 \\
\hline
\end{tabular}

Çizelge 4.Çimento esası dış cephe kaplaması üretimi için gerekli enerji miktarları (Scheuer ve Keoleian, 2002; Kneifel ve Layappa, 2002)

\begin{tabular}{c|c}
\hline Enerji Türü & Değer(MJ) \\
\hline Elektrik(MJ) & $0.857-1.12$ \\
\hline Doğalgaz(MJ) & $2.23-2.26$ \\
\hline Propan(MJ) & $0.014-0.017$ \\
\hline Benzin (MJ) & 0.002 \\
\hline
\end{tabular}

$100 \mathrm{ft}^{2}$ cephe kaplama malzemesi için ortalama \%5'lik kurulum atığı olduğu ve atıkların bir depolama sahasına gireceği varsayılmaktadır. PVC reçine demiryolu ile ortalama 2500 km (1533 mil) taşındığı, diğer malzemeler ise $500 \mathrm{~km}$ uzaklıktan dizel kamyonla taşınmıştır. Üretimi tamamlanmış malzemenin, üretim mekânından ayrılıp şantiyeye ulaşmasındaki taşıma mesafesi yazılımda kullanıcının seçimine bırakılmıştır. Bu kapsamda üretim mekânı ve şantiye arasındaki mesafe $200 \mathrm{~km}$ olarak belirlenmiştir. Ürünlerin taşınma esnasında oluşturduğu çevresel etkiler çalışmada açıklanmıştır.

\subsection{Vinil ve Çimento Esaslı Dış Cephe Kaplama Malzemelerinin Yaşam Döngüsü Etki Değerlendirmesi}

Bu bölümde yaşam döngüsü etki değerlendirmesi, genel çevresel performansı ve etki kategorilerine özgü etki değerleri karşıllaştırmalı incelenmiştir.

\subsection{1. Çevresel performans değerlendirmesi}

Yapı malzemelerinin farklı kategorilerde çevresel etki sınıfları seçilen yazılıma, kuruma ve ülkelere göre değişkenlik göstermektedir. Farklı çevresel sınıfların seçimi bir ürünün sonuç verilerinde büyük farklııkların görülmesine sebep olmaktadır. Çalışmada bu farklılığı belirten çevresel etki sınıflarının farklı kurumların kabul ettiği önem ağırlıklarına göre değerlendirilmesi Çizelge 5'de verilmiştir.

Çizelge 5. Çevresel etki sınıflarına göre farklı kurumların kabul ettiği önem ağılıkları (Scheuer ve Keoleian, 2002; Kneifel ve Layappa, 2002)

\begin{tabular}{lccc}
$\begin{array}{c}\text { ÇEVRESEL PERFORMANS } \\
\text { Çevresel Etki Sınıfları }\end{array}$ & $\begin{array}{c}\text { BEES } \\
\text { Önem Ağırlığı }\end{array}$ & $\begin{array}{c}\text { EPA } \\
\text { Önem Ağırlığı }\end{array}$ & $\begin{array}{c}\text { EŞiT ORANLAR } \\
\text { Önem Ağırlığı }\end{array}$ \\
\hline Küresel Isınma & 29 & 16 & 9 \\
\hline Asitleştirme & 3 & 5 & 9 \\
\hline Ötrofikasyon & 6 & 5 & 9 \\
\hline Fosil Yakıt Tüketimi & 10 & 5 & 9 \\
\hline İç Ortam Hava Kalitesi & 3 & 11 & 8 \\
\hline Çevre Tahribatı & 6 & 16 & 8 \\
\hline Su Tüketimi & 8 & 3 & 8 \\
\hline Hava Kirleticiler & 9 & 6 & 8 \\
\hline Sis & 4 & 6 & 8 \\
\hline Ekotoksisite & 7 & 11 & 8 \\
\hline Ozon Tahribatı & 2 & 5 & 100 \\
\hline İnsan Sağlığı & 13 & 11 & \\
\hline Toplam & 100 & 100 & 8 \\
\hline
\end{tabular}




\subsection{2. Çevresel etki sınıfları kapsamında etki değerlendirmesi}

BEES yazılımı kullanılarak incelenen vinil ve çimento esaslı dış cephe kaplama malzemesinin çevresel performansının belirlenmesine etki eden her bir etki sınıfına ait etki değerleri Çizelge 6 'da verilmiştir. Her bir etki kategorisinin ölçeği, sınıflandırması, kategorizasyonu ve kategorizasyon faktörünün açıklanması ise Çizelge 7 'de verilmiştir.

Çizelge 6. Çevresel etki sınıflarına göre farklı kurumların kabul ettiği çevresel performans değerleri (Scheuer ve Keoleian, 2002; Kneifel ve Layappa,2002)

\begin{tabular}{|c|c|c|}
\hline Küresel Isınma & Vinil Cephe Kaplama & Çimento Esaslı Cephe Kaplama \\
\hline 1.Hammadde & 453.3824 & 1870.9038 \\
\hline 2.Üretim & 71.5483 & 371.2889 \\
\hline 3.Taşıma & 27.8922 & 148.4733 \\
\hline 4.Kullanım & 0.0000 & 45.2680 \\
\hline 5.Bertaraf & 0.0000 & 0.0000 \\
\hline Toplam & 552.8229 & 2435.9340 \\
\hline Asidifikasyon (Mgh+/Birim) & Vinil Cephe Kaplama & Çimento Esaslı Cephe Kaplama \\
\hline 1.Hammadde & 273.8529 & 494.2362 \\
\hline 2.Üretim & 32.3064 & 171.5254 \\
\hline 3.Taşıma & 9.7725 & 52.0198 \\
\hline 4.Kullanım & 0.0000 & 18.2377 \\
\hline 5.Bertaraf & 0.0000 & 0.0000 \\
\hline Toplam & 315.9318 & 736.0191 \\
\hline Ötrofikasyon (G N/Birim) & Vinil Cephe Kaplama & Çimento Esaslı Cephe Kaplama \\
\hline 1. Hammadde & 0.1148 & 0.2498 \\
\hline 2.Üretim & 0.0092 & 0.0486 \\
\hline 3.Taşıma & 0.0099 & 0.0529 \\
\hline 4.Kullanım & 0.0000 & 0.0279 \\
\hline 5.Bertaraf & 0.0000 & 0.0000 \\
\hline Toplam & 0.1339 & 0.3792 \\
\hline Fosil Yakıt Tüketimi (Mj/Birim) & Vinil Cephe Kaplama & Çimento Esaslı Cephe Kaplama \\
\hline 1.Hammadde & 1.3429 & 1.0233 \\
\hline 2.Üretim & 0.0492 & 0.5245 \\
\hline 3.Taşıma & 0.0485 & 0.2579 \\
\hline 4.Kullanım & 0.000 & 0.1154 \\
\hline 5.Bertaraf & 0.000 & 0.000 \\
\hline Toplam & 1.4406 & 1.9211 \\
\hline Su Kullanımı (L/Birim) & Vinil Cephe Kaplama & Çimento Esaslı Cephe Kaplama \\
\hline 1.Hammadde & 42.7801 & 33.9136 \\
\hline 2.Üretim & 0.3955 & 2.2474 \\
\hline 3.Taşıma & 0.0148 & 0.0787 \\
\hline 4.Kullanım & 0.0000 & 44.8006 \\
\hline 5.Bertaraf & 0.0000 & 0.0000 \\
\hline
\end{tabular}


Journal of Architectural Sciences and Applications, 2021, 6 (2), 494-508.

\begin{tabular}{|c|c|c|}
\hline Toplam & 43.1904 & 81.0403 \\
\hline Ekotoksisite (G 2,4-D /Birim) & Vinil Cephe Kaplama & Çimento Esaslı Cephe Kaplama \\
\hline 1.Hammadde & 1.9726 & 19.1662 \\
\hline 2.Üretim & 0.1674 & 0.8708 \\
\hline 3.Taşıma & 0.0369 & 0.1965 \\
\hline 4.Kullanım & 0.0000 & 0.3228 \\
\hline 5.Bertaraf & 0.0000 & 0.0000 \\
\hline Toplam & 2.1769 & 20.5563 \\
\hline Sis (G Nox/Birim) & Vinil Cephe Kaplama & Çimento Esaslı Cephe Kaplama \\
\hline 1.Hammadde & 2.1074 & 6.5354 \\
\hline 2.Üretim & 0.2505 & 1.7634 \\
\hline 3.Taşıma & 0.2689 & 1.4312 \\
\hline 4.Kullanım & 0.0000 & 0.2276 \\
\hline 5.Bertaraf & 0.0000 & 0.0000 \\
\hline Toplam & 2.6268 & 9.9576 \\
\hline Kanser (G C6H6/Birim) & Vinil Cephe Kaplama & Çimento Esaslı Cephe Kaplama \\
\hline 1.Hammadde & 0.5617 & 107.8500 \\
\hline 2.Üretim & 0.0455 & 0.3939 \\
\hline 3.Taşıma & 0.0129 & 0.0689 \\
\hline 4.Kullanım & 0.0000 & 0.0666 \\
\hline 5.Bertaraf & 0.0000 & 0.0000 \\
\hline Toplam & 0.6201 & 108.3794 \\
\hline İnsan Sağlığı Kanser Harici (G C7H8/Birim) & Vinil Cephe Kaplama & Çimento Esaslı Cephe Kaplama \\
\hline 1.Hammadde & 595.5402 & 138849.1688 \\
\hline 2.Üretim & 62.5516 & 5943.2072 \\
\hline 3.Taşıma & 9.3349 & 49.6911 \\
\hline 4.Kullanım & 0.0000 & 129.6795 \\
\hline 5.Bertaraf & 0.0000 & 0.0000 \\
\hline Toplam & 667.4267 & 144971.7466 \\
\hline
\end{tabular}

Çizelge 7. Yaşam döngüsü değerlendirme sisteminde kullanılan çevresel etki kategorileri (Scientific Applications International Corporation, 2006)

\begin{tabular}{|c|c|c|c|c|}
\hline Çevresel Etki & Ölçek & Sınıflandırma & Kategorizasyon & Kategorizasyon Faktörü \\
\hline Küresel ısınma & Küresel & $\begin{array}{l}\text { Küresel ısınma } \\
\text { potansiyeli }\end{array}$ & $\begin{array}{c}\text { Karbondioksit } \\
\text { Oranı }\end{array}$ & - \\
\hline Ötrofikasyon & Yerel & $\begin{array}{c}\text { Fosfat (PO4) } \\
\text { Nitrojenoksit (NO) } \\
\text { Amonyak (NH4) } \\
\end{array}$ & $\begin{array}{l}\text { Ötrofikasyon } \\
\text { Potansiyeli }\end{array}$ & $\begin{array}{c}\text { YDE verisini fosfat eşdeğerlerine } \\
\text { dönüştürür. }\end{array}$ \\
\hline $\begin{array}{l}\text { Fosil Yakıt } \\
\text { Tüketimi }\end{array}$ & $\begin{array}{c}\text { Küresel } \\
\text { Bölgesel } \\
\text { Yerel }\end{array}$ & Küresel & $\begin{array}{l}\text { Kaynak Tüketimi } \\
\text { Potansiyeli }\end{array}$ & $\begin{array}{l}\text { YDE verisini kullanılan kaynağın } \\
\text { miktarına karşın rezervde kalan } \\
\text { kaynağın miktarına dönüştürür. }\end{array}$ \\
\hline Su kullanımı & $\begin{array}{l}\text { Bölgesel } \\
\text { Yerel }\end{array}$ & $\begin{array}{l}\text { Su kullanımı veya } \\
\text { tüketimi }\end{array}$ & $\begin{array}{l}\text { Su Kıtlığı } \\
\text { Potansiyeli }\end{array}$ & $\begin{array}{l}\text { YDE verisini kullanılan kaynağın } \\
\text { miktarına karşın rezervde kalan } \\
\text { kaynağın miktarına dönüştürür }\end{array}$ \\
\hline
\end{tabular}




\begin{tabular}{|c|c|c|c|c|}
\hline Fotokimyasal Sis & Yerel & $\begin{array}{c}\text { Metan olmayan } \\
\text { hidrokarbon (NMHC) }\end{array}$ & $\begin{array}{l}\text { Fotokimyasal } \\
\text { Oksidan } \\
\text { Oluşturma } \\
\text { Potansiyeli }\end{array}$ & $\begin{array}{c}\text { YDE verisini metan eşdeğerlerine } \\
\text { çevirir. }\end{array}$ \\
\hline İnsan Sağ|ı̆̆ı & $\begin{array}{c}\text { Küresel } \\
\text { Bölgesel } \\
\text { Yerel }\end{array}$ & $\begin{array}{l}\text { Havaya, Suya Ve Toprağa } \\
\text { Yapılan Toplam Salımlar }\end{array}$ & LC50 & $\begin{array}{l}\text { LC50 verisini eşdeğerlere dönüştürür; } \\
\text { açığa çıkarma ve multimedya } \\
\text { modelleme kullanır. }\end{array}$ \\
\hline Asidifikasyon & Bölgesel Yerel & $\begin{array}{c}\text { Sülfüroksitler (SOx) } \\
\text { Nitrojenoksitler(NOx) } \\
\text { Hidroklorik asit (HCL) } \\
\text { Hidroflorik asit (HF) } \\
\text { Amonyak (NH4) } \\
\end{array}$ & $\begin{array}{l}\text { Asidifikasyon } \\
\text { potansiyeli }\end{array}$ & $\begin{array}{l}\text { YDE verisini hidrojen iyonu } \\
\text { eşdeğerlerine dönüştürür. }\end{array}$ \\
\hline Su Kullanımı & Bölgesel & $\begin{array}{l}\text { Su kullanımı veya } \\
\text { tüketimi }\end{array}$ & $\begin{array}{l}\text { Su kıtlı̆̆ı } \\
\text { potansiyeli }\end{array}$ & $\begin{array}{l}\text { YDE verisini kullanılan kaynağın } \\
\text { miktarına karşın rezervde kalan } \\
\text { kaynağın miktarına dönüştürür. }\end{array}$ \\
\hline
\end{tabular}

Çevresel etki sınıfları küresel, bölgesel ve yerel etkiler kapsamında sınıflandırılması Şekil 5'de gösterilmiştir.

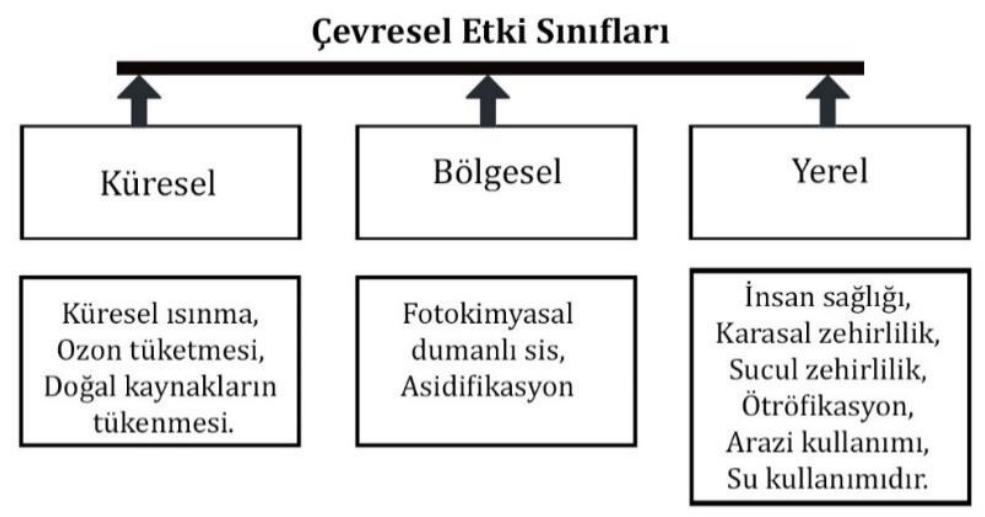

Şekil 5.Çevresel etki sınıfları (Scientific Applications International Corporation, 2006)

Malzemelerin oluşumu sırasında kullanılan yenilenebilir ve yenilenemez enerji kullanımı Çizelge 8'de, özet grafik ise Çizelge 9 'da gösterilmiştir.

Çizelge 8. Malzemelerin üretim sürecinde kullanılan yakıt yenilenebilirliği

\begin{tabular}{lcc}
\hline \multicolumn{1}{c}{ Yakıt Yenilenebilirliği } & Vinil Cephe Kaplama & \multicolumn{1}{c}{ Çimento Esaslı Cephe Kaplama } \\
\hline Yenilenebilir Enerji & 0.1691 & 3.1552 \\
\hline Yenilenemez Enerji & 11.7078 & 19.7703 \\
\hline Toplam & 11.8769 & 22.9255 \\
\hline
\end{tabular}

Çimento esaslı cephe kaplaması yenilenebilir ve yenilenemez enerji kullanımı açısından vinil cephe kaplamasına göre daha yüksek etki değerine sahiptir. Dolayısıyla çimento esaslı cephe kaplamasının yaşam döngüsü sürecinde vinil cephe kaplamasına göre daha çok enerji tüketilmektedir.

Çizelge 9. Malzemelerin ekonomik, çevresel ve tüm performans değerlerine göre özeti

\begin{tabular}{lcc}
\hline \multicolumn{1}{c}{ Ekonomik Performans } & Vinil Cephe Kaplama & \multicolumn{1}{c}{ Çimento Esaslı Cephe Kaplama } \\
\hline İlk maliyet & 2.01 & 3.50 \\
\hline Gelecekteki maliyet-\%2.7 & 0.00 & 1.00 \\
\hline \multicolumn{1}{c}{ Çevresel Performans } & Vinil Cephe Kaplama & Çimento Esaslı Cephe Kaplama \\
\hline Asidifikasyon- 3 \% & 0.0000 & 0.0000 \\
\hline Hava Kirliliği -\%9 & 0.0000 & 0.0001
\end{tabular}




\begin{tabular}{lcc} 
Ekotoksisite -\%7 & 0.0000 & 0.0000 \\
\hline Ötrofikasyon -\%6 & 0.0000 & 0.0001 \\
\hline Fosil Yakıt Tüketimi -\%10 & 0.0004 & 0.0005 \\
\hline Küresel Isınma-\%29 & 0.0006 & 0.0028 \\
\hline Habitat Değişikliği-\%6 & 0.0000 & 52.0198 \\
\hline İnsan Toksisitesi-Kanser \%8 & 0.0000 & 18.2377 \\
\hline $\begin{array}{l}\text { Insan Toksisitesi-Kanser olmayan } \\
\text { \%5 }\end{array}$ & 0.0000 & 0.0000 \\
\hline İ̧ Hava Kalitesi -\%3 & 0.0000 & 0.0000 \\
\hline Ozon tabakası incelmesi -\%2 & 0.0000 & 0.0000 \\
\hline Smog -\%4 & 0.0001 & 0.0003 \\
\hline Su tüketimi -\%8 & 0.0007 & 0.0012 \\
\hline Toplam & 0.0018 & 0.0050 \\
\hline \multicolumn{1}{c}{ Genel Performans } & Çimento Esaslı Cephe Kaplama \\
\hline
\end{tabular}

Çimento esaslı cephe kaplaması yaşam döngüsü sürecinde ekonomik performans açısından vinil cephe kaplamasına göre daha yüksek etki değerine sahiptir. Çimento esaslı cephe kaplaması yaşam döngüsü sürecinde çevresel performans açısından vinil cephe kaplamasına göre daha yüksek etki değerine sahiptir. Çimento esaslı cephe kaplama malzemesinin yaşam döngüsü içerisinde çevresel performans değeri daha yüksek dolayısıyla çevreye daha çok zarar verdiğine ulaşıımıştır.

\section{Değerlendirme ve Sonuç}

Çalışma kapsamında vinil ve çimento esaslı cephe kaplama malzemelerinin çevresel performans değerleri çeşitli kategorilerde analiz edilmiştir. Yapı malzemelerinin çevresel etki değerlendirilmesinde önemli çevresel değerlerin ölçülmesi aşaması yaşam döngüsü değerlendirilmesinin ilk aşamasıdır. Bu kapsamda malzemelerin değerlendirildiği çevresel kriterler:

- Su yüzeyindeki asidifikasyon değerleri,

- Hava kirliliğine etki değeri,

- Çevresel kimyasalların etki değeri (ekotoksisite),

- Göl ekosisteminde besinlerin artması sonucunda alglerin oluşumunun etki değeri (ötrofikasyon),

- Fosil yakıt tüketimi değeri,

- Küresel ısınma değeri,

- Habitat değişim değeri,

- Insanlarda kansere sebep olan toksisite değeri,

- Insanlarda kansere sebep olmayan toksisite değeri,

- İç hava kalitesi değeri,

- Ozon tabakası incelmesi değeri,

- Duman oluşum değeri (smog),

- Su tüketimi değeridir.

Vinil ve çimento esaslı cephe kaplama malzemelerinin yaşam döngüsü boyunca çevreye verdikleri etkilerin değerlendirildiği bu çalışmada BEES veri tabanından elde edilen ekonomik ve çevresel performans değerleri sırasıyla, 
- Çimento esaslı dış cephe kaplama malzemesi ekonomik performans açısından değerlendirildiğinde vinil esaslı dış cephe kaplama malzemesine göre etki değeri yüksektir, dolayısıyla üretim maliyeti daha yüksektir. Çimento esaslı cephe kaplama malzemesinin ekonomik performansı 4.50, vinil dış cephe kaplama malzemelerinin ekonomik performansı ise 2.01 dir. Bu durum çimento esaslı cephe kaplama malzemesinin hammadde üretimi sürecinde ihtiyaç olan malzemenin fazlalığından kaynaklanmaktadır.

- Çimento esaslı dış cephe kaplama malzemesi çevresel performans açısından değerlendirildiğinde vinil esaslı dış cephe kaplama malzemesine göre etki değeri yüksektir, dolayısıyla çevreye verdiği zarar daha yüksektir. Çimento esaslı cephe kaplama malzemesinin çevresel performansı 66.8, vinil dış cephe kaplama malzemelerinin ekonomik performansı ise 26.6876 dır. Malzemelerin çevresel performanslarındaki bu farklılık ihtiyaç olan malzemenin çokluğu ve ürünün elde edilme sürecindeki girdi çıktılarının fazla olmasından kaynaklanmaktadır.

- Vinil cephe kaplama malzemesi çevresel performans parametrelerinden küresel ısınma, asidifikasyon, su kullanımı ve insan sağlığı kriterlerin de daha fazla etki değerine sahiptir, dolayısıyla çevreye verdiği zarar daha yüksektir.

- Çimento esaslı cephe kaplama malzemesi çevresel performans parametrelerinden küresel ısınma, ekotoksisite, asidifikasyon, kanser oluşumlu insan sağlığı ve kanser olumsuz insan sağlığı kapsamında ise daha fazla etki değerine sahiptir, dolayısıyla çevreye verdiği zarar daha yüksektir.

\section{Teşekkür ve Bilgi Notu}

Makalede, ulusal ve uluslararası araştırma ve yayın etiğine uyulmuştur. Çalışmada etik kurul izni gerekmemiştir.

\section{Yazar Katkısı ve Çıkar Çatışması Beyan Bilgisi}

Makalede tüm yazarlar aynı oranda katkıda bulunmuştur. Herhangi bir Kişi/Kişiler ile çıkar çatışması bulunmamaktadır.

\section{Kaynaklar}

Bekker, A.C.M., ve Verlinden, J.C. (2018). Life cycle assessment of wire + arc additive manufacturing compared to green sand casting and CNC milling in stainless steel. Journal of Cleaner Production, 177, 438-447. doi:10.1016/j. jclepro.2017.12.148

Buyle, M., Breat, J., Audenaret, J. (2013). Life cycle assessment in the construction sector: a review. Renewable Sustainable Energy Reviews, 26, 379-388. doi: 10.1016/j.rser.2013.05.001

California Environmental Protection Agency, Integrated Waste Management Board, 1999 (CIWMB), (2000). Designing with vision: a technical manual for materials choices in sustainable construction, ABD: California Integrated Waste Management Board.

Certain Teed Corporation, (2021,Ocak 15). Curb Appeal That Lasts.15 Ocak 2012 tarihinde https://www.certainteed.com/siding/ adresinden erişildi.

Çelebi, G., Gültekin, A. (2016). Yaşam döngüsü değerlendirme yöntemi kapsamında yapı ürünlerinin çevresel etkilerinin değerlendirilmesine yönelik bir model önerisi. Düzce Üniversitesi Bilim ve Teknoloji Dergisi, 3, 1-36. Erişim adresi: https://dergipark.org.tr/tr/download/articlefile/224887

Finnveden, G., Hauschild, M.Z., Ekvall, T., Guinee, J., Heijungs, R., Hellweg, S., Koehler, A., Pennington, D., Suh, S. (2009). Recent developments in life cycle assessment. Journal of Environmental Management, 91, 1-21. doi:10.1016/j. jenvman.2009.06.018

Guinee, J.B., Heijungs, R., Huppes, G., Zamagni, A., Masoni, P., Buonamici, R., Ekvall, T., Rydberg, T. (2011). Life cycle assessment: past, present, and future. Environmental Science and Technology Journal, 45, 90-96. doi:10.1021/es101316v

Greig, A.L., Kneifel, J.D. (2021). BEES Please: Questionnaire User Guide (Teknik rapor). NIST: National Institute of Standards and Technology web sayfasından erişildi: 
https://www.nist.gov/system/files/documents/2020/03/10/BEES-Please-

QuestionnaireUserGuide.pdf

Hunkeler, D., Lichtenvort, K., Rebitzer. G. (2008). Environmentallife cycle costing. Pensacola:SETAC FL (US) in collaboration with CRC Press.

ISO 14040, 2006. Environmental Management - Life Cycle Assessment - Principles and Framework, International Organization for Standardization, İsviçre.

Kaypak, Ş. (2011). Küreselleşme Sürecinde Sürdürülebilir Bir Kalkınma İçin Sürdürülebilir Bir Çevre. Karamanoğlu Mehmetbey Üniversitesi Sosyal Ve Ekonomik Araştırmalar Dergisi, 2011 (1) , 1933. Retrieved from https://dergipark.org.tr/tr/pub/kmusekad/issue/10216/125569

Klöpffer, W. (1997). Life cycle assessment. Environmental Science and Pollution Research, 4, 223-228. doi:10.1007/bf02986351

Kneifel, J. ve Layappa, P. (2021,10 Ocak). Software BEES. NIST: National Institute of Standards and Technology web sayfasından erişildi: https://www.nist.gov/services-resources/software/bees

Lippiatt, B. C., (2002). "BEESC 3.0, "Building for Environmental and Economic Sustainability Technical Manual and User Guide", NISTIR 6916, National Institute Standards and Technology of (NIST), Washington D. C.

Özgünler, M., Acun, Ö. S., Arpacıoğlu, Ü. (2014). Yeşil bina sertifikalarında afet ve yangın güvenliği. Sürdürülebilir Enerji Etkin Binalar (Seeb-Tr) Lansman ve Sempozyumu. İstanbul, Türkiye.

Öztaş, S., Tanaçan, L. (2017). Türk yapı malzemesi sektörü için geliştirilen yaşam döngüsü etki değerlendirme modelinin sınanması. TÜBAV Bilim Dergisi 10,65-76. Erişim adresi: https://dergipark.org.tr/tr/pub/tubav/issue/27937/318242

Scheuer CW, Keoleian GA. (2002). Evaluation of LEEDTM using life cycle assessment methods. Washington: National Institute of Standards and Technology, and Technology Administration, US Department of Commerce, pp $14-17$.

Scientific Applications International Corporation (SAIC), (2006). Life Cycle Assessment: Principles and Practice. Oha: U.S. Environmental Protection Agency (USEPA).

Yıldız, B. (2017). Cam Elyaf Takviyeli Beton (GFRC) Cephe Panelleri İçin Yaşam Döngü Değerlendirmesi (YDD) Yöntemiyle Bir Sürdürülebilirlik Çerçevesi Geliştirilmesi (Doktora tezi). YÖK tez merkezinden edinilmiştir (488040).

Yılmaz, E. ve Arslan, H. (2018). Poliüretan ve Taşyünü Dolgulu Kompozit Panellerin Çevresel Performanslarının İrdelenmesi. 9. Ulusal Çatı \& Cephe Konferansı. İstanbul, Türkiye. 